\title{
PÍO BAROJA: TIERRA VASCA (UNA INTROSPECCIÓN ANTROPOLÓGICA)
}

Iñaki Vázquez Larrea

Universidad Pública de Navarra

http://dx.doi.org/10.5209/NOMA.56570

"¿Por qué produce melancolía recordar estas cosas que fueron? ¿Por qué hay en esa melancolía un extraño encanto? $\dot{2}$ Es mejor saber que esa torre o ese rincón tienen una historia, o es preferible contemplarlos como el campesino que vuelve de su trabajo? ¿Es mejor vivir entre cosas viejas, doradas por el sol de los recuerdos, o entre cosas recién nacidas que emergen de la nada?. Realmente es difícil resolverlo. Más difícil ahora. En este momento, en que se acerca la noche, en que suenan las campanas del Ángelus, murmura el arroyo con más fuerza y una estrella blanca comienza a brillar en el cielo..." (Pío Baroja, El País Vasco)

"No comprendo por qué razones me sentí desde joven vasquista" (Pío Baroja, El País Vasco)

Afirmaba Don Julio Caro Baroja, que su tío Pío era más un hombre del siglo XIX que del XX, y ello por dos cuestiones. Pío Baroja pensaba que la Humanidad había perdido el timón en el siglo XX, y que este último siglo, dominado por los ismos, era menos interesante y novelable que el XIX. En palabras del propio Julio Caro Baroja: "De hecho fue encerrándose más y más cuanto más viejo se hizo: ya a partir del final de la primera guerra mundial. Hacia 1925 mi tío Pío tenía unas ideas y unos gustos que difícilmente casaban con los que dominaban en España. Para él toda la pintura posterior al impresionismo era pura estupidez. La música de Wagner no le gustaba mucho, pero la posterior la juzgaba incómoda. La poesía española, en conjunto, no le interesaba salvo la muy antigua. Tampoco estimaba mucho a los prosistas y novelistas de su época o algo anteriores, con la excepción de Azorín y Ortega...La novela de su época, en conjunto, le interesaba 
poco, porque creía que la novela la hace tanto un tipo de sociedad como el novelista y creía que la sociedad del siglo $X I X$ en sí era más novelesca o novelable que la del XX, técnica, pedantesca, teorizante en todo, dominada por la receta, es decir, el "ismo".

Freud le produjo irritación. Proust le aburrió. Gide le causó una mezcla de admiración y repugnancia. Pasaron por sus manos Joyce, Lawrence, Huxley...Al final estimaba sobremanera a Colette y a J.Green entre los contemporáneos. Contra León Daudet creía que el siglo XX era verdaderamente estúpido, no el anterior" (Julio Caro Baroja, Los Baroja, p. 76).

Julio Caro Baroja, define a su tío como un personaje dieciochesco, de talante liberal chapado a la antigua, no dogmático y agnóstico, que rehuía cualquier gran sistema político, religioso, filosófico o científico, por ocultar, frecuentemente, una abierta mediocridad o falsedad, difícilmente insertable, por tanto, en la generación del 98.

Pío Baroja soñaba con lo imposible en el siglo XX. Una sociedad decimonónica regida por méritos individuales. Más prerromántico, que romántico por tanto. Más dado al culto a Los Héroes de Carlyle, que a los grandes ismos. Donde la pasión por la vida prevalece por encima de cualquier dogmatismo. No en vano, en su epitafío, Julio Caro Baroja dijo de su tío que era el mejor novelista español del siglo XX, y el último español del siglo XIX (Julio Caro Baroja, Semblanza de Pío Baroja).

A lo largo de toda su obra de invención Pío Baroja estableció nítidas diferencias étnicas, culturales y psicológicas entre vascos y españoles, al tiempo que atribuye cualidades más positivas al vasco que al español. Esencializó al pueblo vasco, al paisaje y a sus gentes. En realidad, lo que le alejaba del nacionalismo de Sabino Arana y det carlismo, no era tanto su noción de país (que en gran parte compartía), como la aversión por la maketización o extranjerización del país, sino su ultramontanismo católico (derivado de sus lecturas nietzscheanas).

En Nuevo Tratado de Arlequín (1903) escribe: "El bizkaitarrismo y el carlismo, extendiendo la acción católica por el país, han 
matado al pueblo vasco (...). La región vasca es hoy un baluarte del ultramontanismo. El bizkaitarrismo no moviliza vascos contra castellanos, sino Pérez contra Pérez, Colomas contra Colomas, maketos contra maketos". Mientras que en el Cura de Monleón (1936), hace decir al cura que "Yo no soy más que vasco", después de un sermón tan tosco como auténtico sobre la diferencia de las costumbres de la gente del país y los de fuera (los maketos)

Identificaba lo vasco con lo rural (la ciudad se le antojaba vulgar), amenazado por el industrialismo, la consiguiente decadencia del carácter de la raza vasca (en el sentido fichteano del término) y el moribundo estado del euskera a principios del siglo XX (Eloy L. Placer, Lo vasco en Pío Baroja)

Ello determina, parcialmente, la visión pesimista, desengañada y regresiva que proyecta sobre el presentismo de una sociedad vasca dominada por los ismos. No en vano, su amor patrio vasco (en sus propias palabras, vasquismo juvenil) está teñido de un no disimulado melancólico romanticismo regresivo. La Casa de Aizgorri (1900) presenta un continuo contraste entre el paisaje bucólico de la otrora poderosa estirpe nobiliar guerrera o jauntxos y la decadencia presentista vasca, abocada al incendio de la lucha de clases, en la que Baroja no muestra simpatía por ninguna de las partes en liza: "Van después de olfatear la presa. Ahora empezará la lucha. Veremos quién vence. Águeda lo quiere. Eso basta. Aquí está el fundador, Machín de Aizgorri, el guerrero que sembró el espanto en toda Guipúzcoa. ¡Pobre Hombre! ¡Cómo degeneró su casta! Al cabo de cientos de años, la savia enérgica de los Aizgorris no produce más que plantas enfermas y venenosas" (Pío Baroja, Tierra Vasca, p.74).

De la misma manera que el liberalismo y la modernidad acarrean la ruina moral y económica del retrato organicista y osiánico del que, siglos atrás, fuera esplendor nobiliar vasco del Mayorazgo de Labraz (1902): "En nuestra ciudad, los hidalgos vivían conforme a su condición. Los pobres tomaban la leña que necesitaban en los pinares de los frailes y trabajaban en las heredades de los ricos. La desamortización echó a los cartujos del monasterio; cambiaron las costumbres, 
vinieron nuevos usos, nuevas ideas; las familias hidalgas se arruinaron o huyeron a la capital; las nobles casas solariegas sirvieron de pajares; Labraz empezó a despoblarse" (Pío Baroja, Tierra Vasca, p.120). La novela culmina con un destino trágico, la del último jauntxo o hidalgo que se ve abocado al destierro forzoso de Labraz.

El mismo destino trágico comparte Zalacaín El Aventurero (1908). Nuestro héroe de acción vascongado (heredero de un antiguo linaje guerrero linajudo, venido a menos, con claras reminiscencias de Walter Scott), no se casa ni con liberales ni con carlistas, se impregna de liberalismo francés y observa con espíritu crítico el atraso de sus propios paisanos vascos. Sigue los consejos de su tío Tellagorri y se hace comerciante, para ver finalmente su vida truncada por los odios ancestrales y el fanatismo de sus propios vecinos de Urbia (cae batido de un tiro carlista por la espalda). La obra sirve, a su vez, de marco de reflexión para el propio autor, que lamenta el apego a las viejas ideas de sus compatriotas vascos, y proyecta, a su vez, la visión organicista barojiana de la sociedad vasca, no exenta de mitología historicista tubalista: "Los vascos, siguiendo las tendencias de su raza, marchaban a defender lo viejo contra lo nuevo. Así habían peleado en la antigüedad contra el romano, contra el godo, contra el árabe, contra el castellano, siempre a favor de la costumbre vieja y en contra de la idea nueva. Estos aldeanos y viejos hidalgos de Vasconia y de Navarra, esta semiaristocracia campesina de las dos vertientes del Pirineo creían en aquel Borbón vulgar, extranjero y extranjerizado, y estaban dispuestos a morir para satisfacer las ambiciones de un aventurero tan grotesco" (Pío Baroja, Tierra Vasca, p.335).

La Leyenda de Juan de Alzate (1922) es un poema novelado. Pío Baroja nos retrotrae a una Arcadia rural vasca medieval pagana, regida por la estirpe nobiliar y guerrera de Los Alzate, cuyo genio nacional o Volkgeist se encuentra al borde de la implosión, debido a la intromisión castellano/maketizante del catolicismo. Baroja entona un Finis Vasconiae: "Y a nosotros (los vascos) nos dominaran también esos curas histriónicos con sus dioses judíos, y llegará un día en que Alzate tenga 
una iglesia cultora con sus campanas, que nos despertarán cuando estemos durmiendo. i Finis Vasconiae! Hasta yo quiero decir palabras en latín ¡Qué miseria!" (Pío Baroja, Tierra Vasca, p.473).

El mensaje que subyace es el siguiente, se puede ser netamente vasco sin ser nacionalista, ni tan siquiera cristiano. En clara contraposición al lema sabiniano de Jaungoikoia eta Lagi Zaharra (Dios y Leyes Viejas), Thor (Dios vasco pagano) y libertad. Pese al triunfo del catolicismo, y la muerte de Jaun (protagonista pagano de la obra) su espíritu no ha muerto: "Voy a decir que Jaun no ha muerto; que yo he llenado su ataúd con tierra, y que Jaun vive, y que no morirá; que yo lo he escondido en una cueva del monte Larrun, y que vivirá mientras el país vasco sea esclavo de los católicos, y que cuando llegue el momento, Jaun aparecerá con el martillo de Thor a romper en pedazos el mundo de la hipocresía y del servilismo, y a implantar el culto de la libertad y de la naturaleza" (Pío Baroja, Tierra Vasca, p.635). En suma, en palabras de Pío Baroja, una República del Bidasoa independiente: "sin moscas, sin frailes y sin carabineros" (Pío Baroja, Tierra Vasca, p. 519).

A modo de conclusión, es indudable que Baroja amaba al pueblo vasco, pero a diferencia de la mayoría de sus contemporáneos vascos lo hacía con otros fundamentos de apego. Convendría no olvidar las palabras del gran lingüista Koldo Mitxelena al respecto: "A mi juicio, no es posible negar que Baroja amaba al País Vasco: amaba nuestros cielos, tierras y mares, amaba a nuestra gente, nuestra manera de ser, nuestra probidad, nuestra forma de hablar tanto en euskera como en castellano...Eso sí: los fundamentos de su apego al País Vasco no eran exactamente los de muchos vascos, ni quizá tampoco los de la mayoría de ellos. Y precisamente eso es lo que empaña la visión de algunos" (Koldo Mitxelena, entre nosotros, p. 278) 


\section{BIBLIOGRAFÍA:}

BAROJA, P: Tierra Vasca, Espasa, Barcelona, 2016.

BAROJA, P: El País Vasco, Txalaparta, Tafalla, 2006.

BAROJA, P: El árbol de la Ciencia, Alianza, Madrid, 2012.

BAROJA, P: El Cura de Monleón, Txertoa, San Sebastián, 1971.

BAROJA, P: El Nuevo Tratado de Arlequín, Caro Raggio, Madrid, 1982.

BAROJA, P: Cuentos, Alianza, Madrid, 2015.

CARO BAROJA, J: Los Baroja, Taurus, Madrid, 1972.

CARO BAROJA, J: Semblanza de Pío Baroja, Ediciones 98, Madrid, 2011.

CARO BAROJA, P: Guía de Pío Baroja (El mundo barojiano), Caro Raggio, Madrid, 1987.

MITXELENA, K: Entre nosotros, Alberdania, Irun, 2001.

PLACER, L.E: Lo vasco en Pío Baroja, Ekin, Buenos Aires, 1968.

SÁNCHEZ OSTIZ, M: Pío Baroja, A Escena, Espasa Calpe, Madrid, 2006.

IÑAKI VAZQUEZ LARREA, Profesor Asociado de Sociología en UPNA (Universidad Pública de Navarra). 


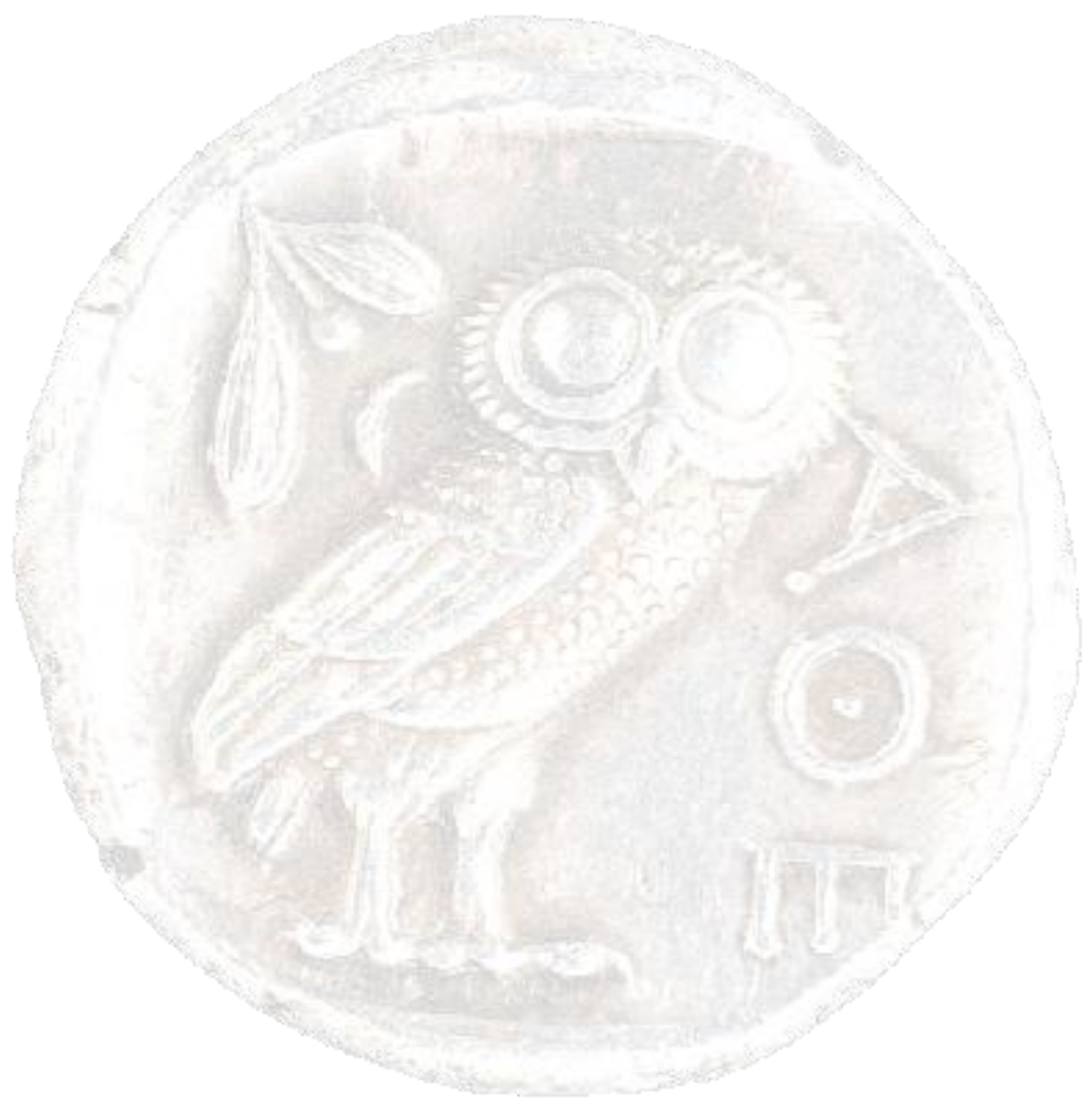

EMUI_EuroMedUniversity | ISSN 1578-6730 · Nomads. Mediterranean Perspectives | ISSN 1889-7231

(C) 1999, Román Reyes, Fundador y Director - (c) 2016, Progetto Pier Paolo Pasolini 